\title{
The Predisposing Factors to LOW BACK PAIN IN WORKERS.
}

\begin{abstract}
Low back pain is a common complaint which has a high socio-economic cost. Very little information is available in South Africa on the prevalence, or the factors associated with the development of low back pain. A group of material handlers at a motor vehicle parts distribution centre were randomly sampled into two groups, one who

WALLNER-SCHLOTFELDT PJ, MSc'; STEWART A, BSc, DPE, MSc (Med)

'Department of Physiotherapy, University of the Witwatersrand complained of low back pain and a control group who did not. Both groups completed a structured questionnaire relating to their work environment and underwent a physical examination. Bending and lifting parts from the floor and participation in heavy physical activity were factors associated with reported low back pain in the experimental group as was a decrease in the overall mobility of the lumbar spine $(p<0.001)$ and a decrease in strength of rectus abdominis ( $p, 0.02)$ and the oblique abdominal muscles ( $p<0.04)$.
\end{abstract}

\section{KEYWORDS: BACK PAIN, MATERIALS HANDLING, BENDING, TWISTING, DECREASED RANGE MUSCLE STRENGTH}

\section{This research was submitted to the University of the Witwatersrand in partial fulfilment of the degree MSc(Physiotherapy) Permission to undertake this study was obtained from the Committee for Research on Human Subjects (Medical) of the University of the Witwatersrand, protocol number M940532.}

\section{INTRODUCTION}

Numerous studies have shown that low back pain (LBP) is a common complaint and cause of lost production time in the industrial sector of the economy (Bigos et al , 1986a). This is costly not only to the particular industry but also to the health care providers (Spengler et al, 1986). Workers involved in lifting and material handling are particularly at risk of developing LBP (Frymoyer et al, 1983). No studies were found to identify factors which may predispose material handlers to LBP in South African industries.

The aim of this study was to establish the period prevalence of low back-pain in a group of South African material handlers in a motor vehicle distribution centre, and to identify factors which may be associated with, or predispose to the development of low back pain.

\section{METHODOLOGY}

The subjects were material handlers in a motor vehicle parts distribution centre (PDC) warehouse. This material handling involved the unpacking of containers and trucks containing spare parts for motor vehicles and trucks. These were received from national and international manufacturing centres, and were stored in the warehouse. At a later stage they were collected from different areas of the warehouse and packed into trucks and containers for distribution around the country.

The warehouse was a large building with multiple levels of storage banks. The lower level storage areas could be easily accessed by hand. The high banks were accessed via stairs leading to platforms, by using portable ladders or an "auto picker" (a hydraulic and electrical platform which is operated by the material handler). The parts varied considerably in size ranging from a small box of bolts to engine blocks, truck panels and chassis. Fork lift machines were used to lift and transport very heavy and ungainly parts. The smaller parts were either packed or unpacked into boxes. These boxes were transported from the receiving area to the dispatch area on pallets pulled by small tractors.

The subjects worked in eight areas in the warehouse. Table 1 describes the typical work carried out in each area.

Safety shoes were worn at all times. Formal seating was not provided for the workers for the retrieval or packing process. The workers sometimes sat on boxes in which parts were packed during sorting.

\section{PROCEDURE}

part 1 of the study which was designed to ascertain the prevalence of LBP over the previous six months. One hundred and thirty four people volunteered to take part. All subjects in the study were male, between the ages $23-59$ years.

\section{Part 1}

All participants were requested to sign a consent form. A self administered questionnaire was completed in order to establish the prevalence of reported LBP within the last six months. Eight subjects were excluded due to incomplete information recorded on the questionnaire. A sample of $64 \%$ (126) of the total target work force participated in the prevalence survey. The subjects were then allocated into group 1 if they reported at least one episode of pain in the lumbar region within the last six months. Group 1 accounted for $54(43 \%)$ of the sample of 126 . The subjects who reported no

\section{CORRESPONDENCE:}

$P$ J Wallner Schlotfeldt

Physiotherapy Department Universty of the Witwatersrand

7 York Road, Parktowin 2193

All 196 workers involved in material handling were invited to participate in
Tel: (011) 640-2621

E-mail: Schlotfeldt@us.net 
Table 1. Name of each area and description of typical work activities carried out in the PDC.

\begin{tabular}{|c|c|c|}
\hline $\begin{array}{l}\text { AREA } \\
\text { NUMBER }\end{array}$ & $\begin{array}{l}\text { NAME } \\
\text { OF AREA }\end{array}$ & WORK ACTIVITY DESCRIPTION \\
\hline 1 & Zone 1 & $\begin{array}{l}\text { Storage and retrieval of truck engine and body parts. These are retrieved using either side sitting forklifts or more } \\
\text { often manually using a step ladder. }\end{array}$ \\
\hline 2 & Zone 2 & Storage and retrieval of truck engine and body parts. Autopicker used to reach high banks. Low banks reached manually. \\
\hline 3 & Zone 3 & $\begin{array}{l}\text { Storage and retrieval of sedan and truck parts, e.g. engine blocks and windscreens. Autopicker used to reach high } \\
\text { parts. Low banks reached manually. }\end{array}$ \\
\hline 4 & Zone 4 & $\begin{array}{l}\text { Storage and retrieval of sedan and truck parts of smaller sizes, e.g. gear plates, brake discs etc. Autopicker used to } \\
\text { reach high parts. Low banks are reached manually. }\end{array}$ \\
\hline 5 & Zone 5 & $\begin{array}{l}\text { Smaller sedan and truck parts, e.g. boxes of air filters, spark plugs etc. This area is divided into two sections by a } \\
\text { metal platform that is approximately halfway up to the ceiling of the warehouse. All parts in this section are handled } \\
\text { manually, using ladders to reach higher banks. The section on the ground level also uses the autopicker. Parts and } \\
\text { boxes are transported via a chute from the higher platform level. All parts are sorted on trolleys that have wheels. } \\
\text { The trolleys are either waist level at the highest point with three shelves or they are deep, with sides of approximately } \\
1 \text { metre in height and about } 15 \mathrm{~cm} \text { off the ground. }\end{array}$ \\
\hline 6 & Binning & $\begin{array}{l}\text { All parts are transported to and from the receiving or dispatch area by people in this department. The larger parts } \\
\text { are transported singly and the smaller ones are packed into boxes and are transported by forklifts or tractors that } \\
\text { pull pallets. }\end{array}$ \\
\hline 7 & Dispatch & $\begin{array}{l}\text { Parts or boxes are electronically scanned and recorded on a computer and then packed into containers or trucks for } \\
\text { further distribution. The loads are manually lifted and packed into the trucks. Very heary and ungainly parts, e.g. } \\
\text { engine blocks and chassis are liffed using the forklift. }\end{array}$ \\
\hline 8 & Receiving & $\begin{array}{l}\text { All parts and boxes are off- loaded manually or with a fork lift, depending on size, and placed on pallets for } \\
\text { distribution to various areas of the PDC. }\end{array}$ \\
\hline
\end{tabular}

episode of pain in the lumbar region within the last 6 months were allocated into group 2. There were $72(57 \%)$ in this group.

\section{Port 2}

Thirty subjects were randomly selected from each of the above two groups to participate in part 2 of the survey. Of the 30 subjects selected from group 1 , one subject was excluded due to known kidney pathology being the cause of his LBP and three subjects refused to participate. A total of 26 subjects from group 1 participated in part 2 . They were allocated to group A and all agreed to participate in a structured interview regarding their area of work and pain during daily working activities and a clinical examination which explored physical characteristics of the subject, e.g. flexibility, movement and associated pain.

Of the 30 subjects selected from group 2, two subjects refused to participate and four were involved in industrial strike action during the period of the study. A total of 24 subjects participated in part 2 from group 2. They were allocated to group $\mathrm{B}$ and all agreed to participate in the interview and the clinical examination. It was not in the scope of this study to examine and differentiate the exact nature of the LBP.
The clinical assessment tools used to ascertain mobility and muscle strength of the lumbar spine were chosen as they are simple to perform and require no equipment. The mobility of the lumber spine was assessed according to Maitland (1986). The muscle strength was assessed by manual muscle testing.

\section{STATISTICAL ANALYSIS}

Means, standard deviations and frequency distributions were used to summarise the data. Comparisons were made between groups 1 and 2 and also between groups $A$ and $B$ using the student t-test when continuous variables were being compared. When categorical variables were being compared the chi-square test was used to test for associations between relevant variables. The Mc Nemar test for symmetry was used in order to compare the incidence of pain in different positions within the group with LBP. Data regarding the interview and clinical examination are presented as percentages. A p-value of less than 0.05 was considered to be statistically significant.

\section{RESULTS AND DISCUSSION}

\section{Part 1: Prevalence of LBP over the last six months}

The $43 \%$ of subjects reporting LBP over the previous six months was similar to the finding by Biering-Sorensen (1984) who reported a one year period prevalence of $4 \%$ in a general population aged between 30 and 60 years.

There was no significant difference in the mean age between the subjects in groups $I$ and 2 . The average age of the subjects in both groups in this study is similar to that reported in the study by Frymoyer et al (1983) who found that the majority of their work force subjects who reported moderate to severe back pain was in their thirties. Bigos et al (1986a) reported that employees in the 31-40 age group were most susceptible to "high cost" back injury. As the average age of the subjects in this study falls within these parameters this could explain the high 6 month period prevalence.

Table 2 indicates the percentages of subjects with and without low back pain in each of the eight areas in groups 1 and 2 .

The significantly higher incidence of reported LBP in area 5 could be explained by the fact that the parts that require sorting and packing in this area are smaller and possibly more difficult to locate as many of them are packed into storage boxes. More bending, twisting and lifting is required to locate the small parts and the storage boxes are heavy to move. The sorting of parts is carried out on trolleys, some waist height and some 
Table 2. Percentage of subjects in Groupl and 2 categorised into areas of work.

\begin{tabular}{|c|c|c|c|c|c|c|c|c|c|c|}
\hline GROUP & $\mathrm{n}$ & Freq & 1 & 2 & 3 & 4 & 5 & 6 & 7 & 8 \\
\hline 1 LBP & 54 & $\%$ & 5.6 & 7.4 & 7.4 & 9.3 & 33.3 & 13.0 & 11.1 & 13.0 \\
\hline 2 NLBP & 72 & $\%$ & 16.7 & 6.9 & 9.7 & 6.9 & 12.5 & 4.2 & 25.0 & 18.1 \\
\hline
\end{tabular}

Chi square ( Area 5 ) $\chi^{2}=16.49, \mathrm{df}=7, \mathrm{p}=0.02$ (S), LBP= low back pain, NLBP = no low back pain.

requiring excessive flexion of the thoracic and lumbar spine (Table 1). The fact that this particular area has two distinct levels may cause the material handlers to pass parts between levels manually, thus putting them more at risk of lumbar strain and therefore pain.

Magora (1973) showed that heavy physical work is associated with LBP. Liffing a $10 \mathrm{~kg}$ load increases the load on/the third lumbar disc to $1700-1900$ Newtons (N) (Nachemson, 1981) and lifting a load of $10 \mathrm{~kg}$ in a rotated and forward flexed position increases the load further to $2100 \mathrm{~N}$. Frequent bending, twisting and working in awkward postures, is associated with LBP (Majora, 1973). From this it seems plausible that there is an association between work in area 5 and reported LBP.

\section{Part 2: Results of the structured interview}

From Table 2 it can be seen that the highest proportion of subjects complaining of LBP worked in area 5. The highest number of subjects in group A was drawn from area 5 (Table 3 ). From this it can be concluded that the employees in area 5 had the highest reported incidence of LBP over a 6 month period.

There was no difference between groups $A$ and $B$ in the length of time that the subjects worked in the PDC. Both groups had worked in the PDC for approximately eight years. It has been suggested that material handling for periods of time up to 12 years may not be a factor associated with the prevalence of reported back pain (Frymoyer et al, 1983).

Frymoyer et al (1983), have described lost working hours as a means of quantifying the socio-economic cost of LBP. In this study 15 percent of the subjects in group $\mathrm{A}$ reported absenteeism due to LBP in the previous 6 months. Unlike other studies, the periods of time were very short, ie. 2 days in the case of 3 employees and only 1 day in the case of another. Frymoyer et al (1983), found

Table 3. Frequency distribution of subjects in relation to their work area.

\begin{tabular}{|c|c|c|c|c|}
\hline & \multicolumn{2}{|c|}{$\begin{array}{c}\text { Group A (LBP) } \\
\text { N=26 }\end{array}$} & \multicolumn{2}{c|}{$\begin{array}{c}\text { Group B (NLBP) } \\
\text { n=24 }\end{array}$} \\
\hline Area & Frequency & Percentage & Frequency & Percentage \\
\hline 1 - Zone 1 & 0 & $0 \%$ & 5 & $20.8 \%$ \\
\hline 2 - Zone 2 & 2 & $7.7 \%$ & 2 & $8.3 \%$ \\
\hline 3 - Zone 3 & 0 & $0 \%$ & 1 & $4.2 \%$ \\
\hline 4 - Zone 4 & 3 & $11.5 \%$ & 3 & $12.5 \%$ \\
\hline 5 - Zone 5 & 13 & $50.0 \%$ & 5 & $20.8 \%$ \\
\hline 6 - Binning & 2 & $7.7 \%$ & 0 & $0 \%$ \\
\hline 7 - Dispatch & 2 & $7.7 \%$ & 5 & $20.8 \%$ \\
\hline 8 - Receiving & 4 & $15.4 \%$ & 3 & $12.5 \%$ \\
\hline
\end{tabular}

Table 4. \% Responses of Group A to questions on LBP during particular activities.

\begin{tabular}{|l|c|c|c|}
\hline Activity performed during working hours & Yes & No & " $\mathbf{n}^{\prime *}$ \\
\hline Standing for long periods of time & 61.5 & 38.5 & 26 \\
\hline Sitting & 38.5 & 61.5 & 26 \\
\hline Walking & 26.9 & 73.1 & 26 \\
\hline Bending & 89.4 & 10.5 & 19 \\
\hline Pulling boxes & 88.8 & 11.1 & 18 \\
\hline Sorting parts into boxes or deep trolleys & 90.9 & 9.1 & 22 \\
\hline Sorting parts on a table & 11.7 & 88.2 & 17 \\
\hline Sorting parts onto a waist high trolley & 28.5 & 71.4 & 14 \\
\hline Pushing boxes along the floor & 73.3 & 26.6 & 15 \\
\hline Pulling boxes along the floor & 82.3 & 17.6 & 17 \\
\hline Carrying boxes & 86.3 & 13.6 & 22 \\
\hline Lifting parts from a height & 41.1 & 58.8 & 17 \\
\hline Lifting parts from the ground & 85.7 & 14.2 & 21 \\
\hline Carrying parts & 70.0 & 30.0 & 20 \\
\hline Turning and placing objects - twisting & 60.0 & 40.0 & 25 \\
\hline Pulling parts and boxes on the paller & 58.3 & 41.6 & 12 \\
\hline
\end{tabular}

* $n=$ the number of subjects in which that activity was applicable.

Table 5. Comparison of responses from subjects in Group A to activities described in $\mathrm{i}$ ii and iii.

\begin{tabular}{|l|l|l|}
\hline \multicolumn{2}{|c|}{ Activity } & \multicolumn{1}{c|}{ Statistical values } \\
\hline Standing & Sitting & $\begin{array}{l}\text { Mc Nemar }=3, d f=1, \\
p=0.08(N S)\end{array}$ \\
\hline $\begin{array}{l}\text { Sorting parts into deep trolleys } \\
\text { or boxes }\end{array}$ & $\begin{array}{l}\text { Sorting parts onto a waist } \\
\text { high trolley }\end{array}$ & $\begin{array}{l}\text { Mc Nemar }=8, d f=1, \\
p=0.005(S)\end{array}$ \\
\hline Lifting parts from the ground & Lifting parts from a height & $\begin{array}{l}M c \text { Nemar }=8, d f=1, \\
p=0.005(S)\end{array}$ \\
\hline
\end{tabular}

$\mathrm{S}=$ significant, $\mathrm{NS}=$ not significant

that of the $46 \%$ of subjects complaining of moderate LBP in his survey, a mean of 21 days was lost from work over the previous year. Table 4 illustrates the responses to questions, in percentages, on whether LBP was experienced during particular activities during working hours by the subjects in Group A. 
Table 6. Ability to achieve full range movement.

\begin{tabular}{|c|c|c|c|c|}
\hline Movement & Group & $\begin{array}{c}\text { Full range } \\
\text { achieved }\end{array}$ & $\begin{array}{c}\text { Full range } \\
\text { not achieved }\end{array}$ & p value \\
\hline FlexionA & $*$ & 12 & 14 & \\
\hline & $\mathrm{B}^{* *}$ & 23 & 1 & 0.00043 (S) \\
\hline Extension & $\mathrm{A}$ & 8 & 18 & \\
\hline & $\mathrm{B}$ & 22 & 2 & 0.00004 (S) \\
\hline L. lateral flexion & $\mathrm{A}$ & 12 & 14 & \\
\hline & $\mathrm{B}$ & 23 & 1 & 0.00014 (S) \\
\hline R. lateral flexion & $\mathrm{A}$ & 13 & 13 & \\
\hline & $\mathrm{B}$ & 23 & 1 & 0.00099 (S) \\
\hline L rotation & $\mathrm{A}$ & 10 & 16 & \\
\hline & $\mathrm{B}$ & 21 & 3 & 0.00104 (S) \\
\hline R rotation & A & 8 & 18 & \\
\hline & B & 21 & 3 & 0.00016 (S) \\
\hline
\end{tabular}

*Group A, n= 26; **Group B, n =24; S=Significant

It can be seen from the grey areas in Table 4 that the following activities resulted in more that $60 \%$ of subjects reporting an experience of pain in their lower backs: standing for long periods of time, bending, pulling and pushing boxes along the floor, sorting parts into boxes or deep trolleys, carrying parts and boxes, lifting parts from the ground and turning and placing objects. The findings of this study are in agreement with Magora (1973).

Table 5 shows the significant differences in response rates in Group A for the different activities in $\mathrm{i}$, ii and iii causing pain;

i) "Standing or sitting"

ii) "Sorting parts into deep boxes or trolleys" and "sorting parts onto a waist high trolley"; and

iii) "Lifting parts from the ground" and "lifting parts from a height".

Standing for long periods of time, without the option of sitting for brief intervals according to need or choice, was shown by Magora (1972) to be a factor linked to LBP. Nachemson (1981) showed a $100 \%$ increase in load measurement in the third intervertebral (L3) disc in standing as compared to supine.

The material handlers in the PDC were involved in sorting and retrieval of parts for at least 8 hours a day. A lunch break of 30 minutes and two tea breaks of 15 minutes each were given. Many of the workers worked seven days a week as they were paid more if they worked overtime. A large proportion of their time involved standing and sorting parts into and out of boxes, crates and trol- leys. Sixty one percent of subjects with LBP reported pain during this activity.

Activities such as bending and sorting parts into boxes or deep trolleys was reported by the material handlers to cause LBP in 90 percent of the sample which is in agreement with findings reported by Magora (1973). Similarly Nachemson (1981), reported that the load on the third intervertebral disc in the 40 degree bending position increased from $500 \mathrm{~N}$ to $1000 \mathrm{~N}$ in the standing position. The material handlers spent a large part of their day in this position sorting out small parts from boxes on the floor or deep trolleys and then storing them onto the appropriate shelves. If the worker used a trolley or a table of approximately waist height the reported incidence of LBP during that activity dropped significantly (Table 5). The fact that some subjects still reported pain is probably attributable to prolonged standing.

Parts and boxes are moved from the ground or from the autopicker to the shelves, requiring twisting movements of the lumbar spine. These movements were carried out frequently which could explain the over $60 \%$ reported incidence of LBP during those activities. The incidence of LBP increased during lifting activities and is similar to the findings of Nachemson (1981), where lifting and holding heavy objects increased the load through the lumbar spine to $1900 \mathrm{~N}$.

Carrying heavy boxes caused pain in $86 \%$ of the sample and carrying heavy parts caused pain in $70 \%$ of the sample. The boxes that were carried by the sub- jects varied in weight, the average weight for a filled box being approximately $35 \mathrm{~kg}$. Parts vary in bulk and weight, from fenders to engine blocks.

Numerous authors found a direct link between lifting, low back pain and low back injury (Frymoyer et al, 1983; Bigos et al, 1986a).

Seventy three percent of subjects reported that pushing boxes along the floor caused LBP and $82 \%$ of subjects reported that pulling boxes along the floor caused LBP. Involvement in heavy physical work that requires repetitive lifting, pulling and pushing of heavy objects or turning and placing of heavy objects is associated with the prevalence of LBP in industry, (Magora 1973, Frymoyer et al, 1983). The findings in this study seems to show that the subjects in this study were at risk of developing LBP by the nature of their physical work, due to a possible mismatch between the job demands and the person's physical capacity.

\section{Results of the Physical Examination}

Subjects in groups A and B underwent a physical examination. No significant difference was found between groups A and $B$ with regard to weight or height. This is in keeping with the findings of Bigos et al (1986b).

The range of movement was assessed and recorded in "intervals of quarters of normal expected full range movement" as described by Maitland (1986). This method of assessing spinal mobility of the lumbar area was chosen because of its frequent use in the clinical situation and it requires no specialised equipment.

Significant differences existed between the groups A and B in their ability to achieve a full range movement (Table 6). Group A had significantly less mobility of the lumbosacral spine overall compared to group B, (Table 6). It cannot be said with any degree of certainty whether this lack of mobility is a cause or a consequence of LBP.

The issue of the reliability of the measurement tools to ascertain normal range of movement for the lumbar spine is a controversial one. The test used in this study (Maitland, 1986), is one often employed by physiotherapists in the clinical field. 
Table 7. \% Subjects in each group for MMT of rectus abdominis muscle.

\begin{tabular}{|c|c|c|c|}
\hline Group & \multicolumn{3}{|c|}{ Manual muscle test grade } \\
\hline & $0-3$ & 4 & 5 \\
\hline$A(n=26)$ & 11 & 9 & 6 \\
\hline & $(42.3 \%)$ & $(34.6 \%)$ & $(23.0 \%)$ \\
\hline$B(n=24)$ & 2 & 12 & 10 \\
\hline & $(8.3 \%)$ & $(50.0 \%)$ & $(41.6 \%)$ \\
\hline
\end{tabular}

Chi-square $x^{2}=7.59, \mathrm{df}=2, \mathrm{p}=0.023(\mathrm{~S})$

Table 8. \% Subjects in each group for MMT of the oblique abdominal muscle.

\begin{tabular}{|c|c|c|c|}
\hline Group & \multicolumn{3}{|c|}{ Manual muscle test grade } \\
\hline & $\mathbf{0 - 3}$ & $\mathbf{4}$ & $\mathbf{5}$ \\
\hline $\mathrm{A}(\mathrm{n}=26)$ & 13 & 9 & 4 \\
\hline & $(50,0 \%)$ & $(34.6 \%)$ & $(15.3 \%)$ \\
\hline $\mathrm{B}(\mathrm{n}=24)$ & 4 & 12 & 8 \\
\hline & $(16.6 \%)$ & $(50.0 \%)$ & $(33.3 \%)$ \\
\hline
\end{tabular}

Chi-square $x^{2}=6.46, d f=2, p=0.04(S)$

Manual muscles testing procedures were used to assess muscle strength in all subjects. In order to illustrate the clinical application of the results all subjects with a manual muscle test (MMT) score of 3 (Fair) or less than 3, were categorised together as these subjects were unable to obtain a muscular contraction against resistance.

Table 7 shows that a significantly higher percentage of subjects in group A obtained a grade 3 or less as compared to group $B$ in the test for rectus abdominis strength.

There was a significant difference between groups $\mathrm{A}$ and $\mathrm{B}$ with regards to their oblique abdominal muscle strength as can be seen in Table 8 .

The Chi-square test was used to analyse the differences between groups $\mathrm{A}$ and $\mathrm{B} . \mathrm{S}=$ Significant.

Troup et al. (1981) have shown that the abdominal muscles exhibit weakness in subjects who have LBP. One would expect people involved in material handling on a daily basis to have relatively good abdominal strength and at least be able to obtain a contraction against resistance.

Both the rectus abdominis and oblique abdominal muscles showed significant weakness in group A (Table 7 and 8). However only $41 \%$ of subjects in Group $B$ were able to obtain a full strength contraction of the rectus abdominis muscles and only $33 \%$ a full contraction strength of the oblique abdominal muscles.

The intra-rater reliability of MMT as a tool in the assessment of muscle strength is debatable (Frese et al, 1987; Wadsworth et al, 1987). MMT has the advantage of being clinically versatile and inexpensive to administer, but deviation from the standardised testing procedures and the subjectivity of the grading system are potential sources of error. The test in this study was conducted by a researcher with 10 years of clinical experience. Thus, the results have some clinical value and should not be rejected out of hand.

Both right and left quadriceps muscle groups revealed equal strength in each subject and there was no difference between groups $\mathrm{A}$ and $\mathrm{B}$.

There appears to be a dearth of literature relating quadriceps strength to the presence of LBP. Lifting is carried out on a daily basis in this sample and the quadriceps muscles are well recruited in the lifting process. Concentric and eccentric quadriceps contraction is a vital part of the lifting procedure especially if the crouch lift is employed. Even though no differences were noted in quadriceps strength between groups $A$ and $\mathrm{B}$ it is interesting to note that only $42 \%$ of subjects in group A were able to achieve a full strength (grade 5) contraction as compared to 70 percent in group B. Trafimow et al, (1993) noted that fatigue in the quadriceps muscles caused their subjects to alter their lifting patterns from a squat lift to a stoop lift which did not require as much concentric muscle action.

The MMT results in group A and B for the trunk extensors were similar to those of Flicker et al, (1993) who showed that people with LBP have decreased trunk extensor strength. There was no difference between groups $\mathrm{A}$ and $\mathrm{B}$ and the majority of subjects in both groups could only achieve a grade 4 contraction.

The subjects were all asked to lift a $35 \mathrm{~kg}$ cardboard box, similar to one which would contain motor vehicle parts. Two rdifferent lifting methods were employed, stoop lifting and crouch lifting. There was no difference in the lift employed by groups A and B.

Magora (1973) reported that sudden unexpected movements related to heavy lifting was responsible for the incidence of LBP among his subjects. As no difference was noted between groups $A$ and $B$ the actual lifting method did not seem to be one of the factors that predisposed subjects to LBP.

\section{Limitations of the study:}

The methods employed to ascertain range of lumbar restriction were chosen as quick clinical tests and the results of lumbar mobility should be regarded in this light. Future studies could be employed to use more specific and reliable tools.

This study was conducted in the early part of 1994. Literature subsequent to this (Hodges and Richardson, 1996: Jull et al, 1993) relating to the effect of multifidus and transversus abdominis muscles in relation to their stabilising function and low back pain may have been beneficial and improved the sensitivity of the testing procedures used in this study.

\section{CONCLUSION}

The period prevalence rate of reported low back pain was $43 \%$. Factors found to be associated with the development of low back pain were; activities such as bending to do work near the floor surface, lifting objects from the ground and participation in heavy manual work, i.e. lifting, pushing, pulling and carrying of heavy objects; a decrease in the overall mobility of the lumbar spine and; a decrease in muscle strength of the rectus abdominis and the oblique abdominal muscles.

\section{REFERENCE}

Biering-Sorensen F 1983 A prospective study of low back pain in a general population. ii. Location, character, aggravating and relieving factors. Scandinavian Journal of Rehabilitation Medicine 15:81 - 88.

Bigos S J, Spengler D M, Martin N A, Zeh J, Fisher L, Nachemson A, Wang M H 1986a Back injuries in industry: a retrospective study. ii. Injury factors. Spine 11(3): 246-25I

Bigos S J, Spengler D M, Martin N A, Zeh J, Fisher L, Nachemson A. 1986b Back injuries in industry: a retrospective study. iii. employee related factors. Spine 11(3): 252 
Flicker P L, Fleckenstein J L, Ferry K, Payne J, Ward C, Mayer T, Parkey R W, Peshock R M 1993 Lumbar muscle usage in chronic low back pain. Spine 18(5): 582

Frese E, Brown M, Norton B J 1987 Clinical reliability of manual muscle testing. Middle trapezius and gluteus medius muscles. Physical Therapy 67(7): 1072 -1076

Frymoyer J W, Pope M H, Clements J H, Wilder D G, McPherson B, Ashikaga T 1983 Risk factors in low back pain: An epidemiological survey. The Journal of Bone and Joint Surgery $65-A(2): 213-218$

Hodges P W, Richardson C A 1996 Inefficient stabilisation of the lumbar spine associated with low back pain. Spine 21(22): 2640 - 2650

Jull G, Richardson C, Toppenberg R, Comerford M, Bui B 1993 Towards a mea- surement of active muscle control for lumbar stabilisation. Australian Journal of Physiotherapy 39 (3): 187 - 193

Magora A 1972 Investigation of the relation between low back pain and occupation. iii. physical requirements: sitting, standing and weight lifting. Industrial Medicine $41: 5$ - 9.

Magora A 1973 Investigation of the relation between low back pain and occupation. iv. physical requirements: bending, rotation, reaching and sudden maximal effort. Scandinavian Journal of Rehabilitation Medicine 5: $186-19$

Maitland G D 1986. Vertebral Manipulation. 5th Edition. Butterworths

Nachemson A L 1981 Disc Pressure Measurements. Spine 6(1): 93 - 97
Spengler D M, Bigos S J, Martin N A, Zeh J, Fisher L, Nachemson A 1986 Back injuries in industry: a retrospective study. i. overview and cost analysis. Spine 11(3): 241 - 245

Trafimow J H, Schipplein O D, Novak G J, Andersson G B J 1993 The effects of quadriceps fatigue on the effect of lifting. Spine 18(3): 364 - 367

Troup J D G, Martin J W, Lloyd D C E F 1981 Back pain in industry. A prospective survey. Spine 6(1): 61- 69

Wadsworth C T, Krishnan R, Sear M, Harrold J, Nielsen D H 1987 Intrarater reliability of manual muscle testing and hand-held dynametric muscle testing. 'Physical Therapy 67(9): $1342-1347$ 